\title{
Knowledge and Attitude of General Pakistani Population Towards Antibiotic Resistance
}

\author{
Ramsha Akhund ${ }^{1}$, Fatima Jamshed ${ }^{2}$, Hassam A. Jaffry ${ }^{3}$, Hamza Hanif ${ }^{4}$, Sundus Fareed ${ }^{5}$ \\ 1. General Medicine, Jinnah Sindh Medical University, Karachi, PAK 2. Pediatrics, Jinnah Sindh Medical University, \\ Karachi, PAK 3. Internal Medicine, Jinnah Postgraduate Medical Center, Karachi, PAK 4. Internal Medicine, Jinnah \\ Sindh Medical University, Karachi, PAK 5. Internal Medicine, Civil Hospital, Karachi, PAK
}

Corresponding author: Sundus Fareed, sundus_fareed@yahoo.com

\section{Abstract \\ Introduction}

The emergence and continuous spread of drug resistant bacteria has become one of the leading health concerns globally. Persistent failure to develop and/or discover new antibiotics along with irrational use of existing antibiotics is associated with rise in antibiotic resistance. There is poor understanding of antibiotics usage and their preciousness among the masses which result in careless utilization and hence, the emerging antibiotic resistance. The aim of this study is to evaluate the knowledge and attitude of Pakistanis towards antimicrobial resistance (AMR).

\section{Methods}

This observational cross-sectional survey was designed in the form of an online pro forma circulated in January 2019. It was a self-structured pro forma which included age, gender, and 10 questions - five to assess the knowledge and five to assess the attitude towards AMR. Each question was to be responded with a "Yes" or a "No." For knowledge assessing questions “do not know” was also an option. Data was entered and analysed using SPSS version 22 (IBM Corp., Armonk, NY).

\section{Results}

Of 1,132 participants, 837 (73.9\%) thought that it was alright to stop antibiotics course whenever they felt better, 505 (44.6\%) thought that frequent and unnecessary use of antibiotics actually decrease their effectiveness, and 208 (18.4\%) participants thought it was correct to take antibiotics for cold and influenza. There were 157 (13.9\%) participants who had not followed the duration of treatment as given in their doctor's prescription, 49 (4.4\%) who had changed their antibiotic dose without doctor consultation, 467 (41.3\%) who had reused leftover antibiotics from their previous prescription, $700(61.8 \%)$ who had suggested it to their doctors to prescribe them antibiotics and 378 (33.4\%) participants who had purchased antibiotics without any prescription in the last one year.

Received 03/11/2019

Review began 03/13/2019 Review ended 03/14/2019 Published 03/18/2019

๑) Copyright 2019

Akhund et al. This is an open access article distributed under the terms of the Creative Commons Attribution License CC-BY 3.0., which permits unrestricted use, distribution, and reproduction in any medium, provided the original author and source are credited.

\section{Conclusion}

Pakistani individuals are not as knowledgeable about antibiotic resistance as severe the issue is in this region. Their attitude towards utilization of antibiotics is not very promising. It becomes essential to initiate antibiotic stewardship programs and educate the masses regarding efficacious and safe use of antibiotics in this region.

Categories: Internal Medicine, Infectious Disease, Epidemiology/Public Health

Keywords: knowledge and attitude, antibiotics and antibiotic resistance, antibiotic stewardship, antibiotic prescribing, self-prescription

\section{Introduction}

The emergence and continuous spread of drug resistant bacteria has become one of the leading health concerns not only for humans, but also for animals, plants, and crops; hence the overall environmental health [1]. Antibiotics treatment is one of the main approaches of modern medicine to combat infections. The early $19^{\text {th }}$ century was named "Golden Era" due to discovery of many new antibiotics [2]. However, the golden period did not last for long as the researchers were unable to keep up with the rapidly emerging resistant pathogens. Persistent failure to develop and/or discover new antibiotics along with irrational use of existing antibiotics is predisposing to the emergence of antimicrobial resistance (AMR) [3].

Another major reason for antibiotic resistance is overuse and misuse. Although, medical literature has always strongly advised cautious use of antibiotics, they still remain highly over-prescribed all across the globe. Evidence from various studies has stated that treatment indications, agent choice, and antibiotic therapy duration were not medically correct in $30 \%-50 \%$ of the cases [4, 5]. Irrational antibiotics use does 
not only indicate lack of patient compliance towards physicians' instructions, but inappropriate antibiotic prescription from the physicians is also not uncommon. Correct indication, right drug and dosage, drug of first choice, appropriate period of use, and lower treatment cost, all contribute to rational and judicious antibiotic prescription [6].

Patients and the general population contribute to another important factor leading to antibiotic resistance self-medication [7]. Around $2 / 3^{\text {rd }}$ of all oral antibiotics used globally are taken without prescriptions and are used for incorrect indications such as tuberculosis, malaria, and for childhood viral infections [8].

In a study conducted with physicians, it was seen that $20 \%$ of their antibiotic prescriptions were influenced by their patients' choice and demand [9]. This is reinforced by another study where $40 \%$ individuals believed that antibiotics should be prescribed for all flu-like symptoms and 30-50\% did not understand the difference between antibiotics, antipyretics, and anti-inflammatory drugs [10]. These findings indicate poor understanding of antibiotics usage and their preciousness among the masses which result in careless utilization and hence, the emerging antibiotic resistance. The aim of this study is to evaluate the knowledge and attitude of Pakistanis towards antibiotics resistance.

\section{Materials And Methods}

This observational cross-sectional survey was designed in the form of an online pro forma circulated via social media in January 2019. It was a self-structured pro forma which included age, gender, and 10 questions - five to assess knowledge and five to assess attitude. Each question was to be responded with a "Yes" or a "No." For knowledge assessing questions "do not know" was also an option. Since it was a selfstructured pro forma, its internal reliability was first calculated through a pilot survey $(n=20)$. Data was entered and analysed using SPSS version 22 (IBM Corp., Armonk, NY). Internal reliability deduced via Cronbach alpha was 0.79 . Frequency and percentages were calculated for categorical variables including questions for assessing knowledge and attitude. Mean and standard deviation (SD) were calculated for continuous variable of age.

\section{Results}

One thousand one hundred and thirty-two pro formas were completed. There were 612 (54.06\%) men and 520 (45.94\%) women. The mean age of all participants was $35.84 \pm 11.09$ years.

The responses to knowledge about antibiotics resistance are shown in Figure 1. It shows that 637 (56.3\%) people knew that they could contribute to decrease antimicrobial resistance, 837 (73.9\%) participants thought that it was alright to stop antibiotic course whenever they felt better, 505 (44.6\%) individuals thought that frequent and unnecessary use of antibiotics actually decrease their effectiveness, 700 (61.8\%) thought that bacteria could become resistant to antibiotics over time, and there were 208 (18.4\%) participants who thought it was correct to take antibiotics for cold and influenza (Figure 1).

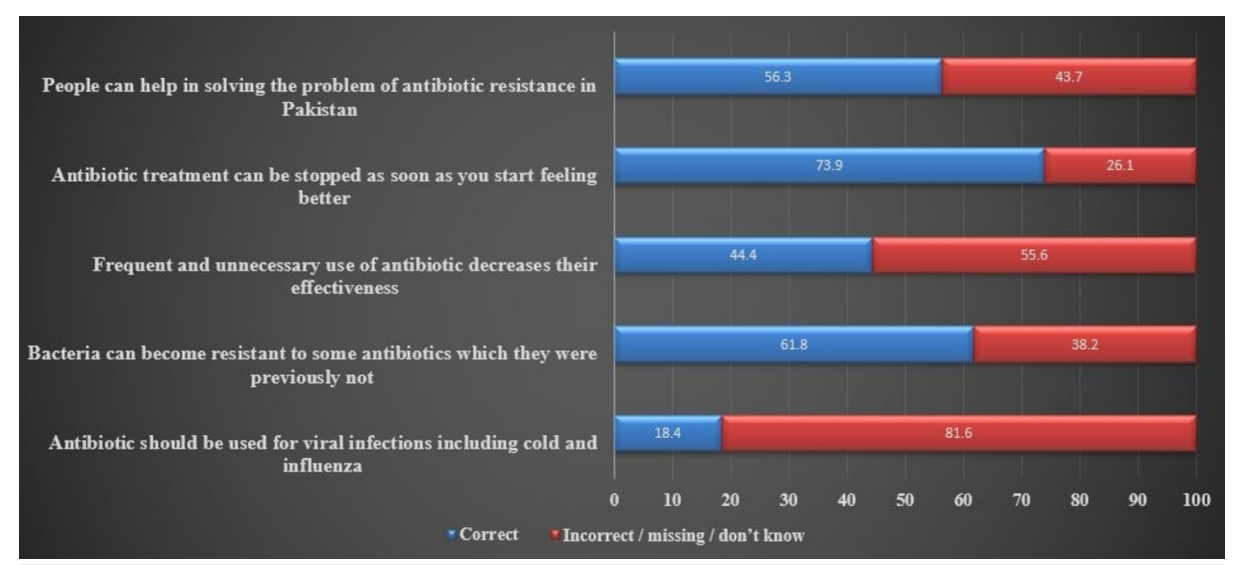

FIGURE 1: Assessment of knowledge about antibiotic resistance (\%).

The attitude of the participants towards antibiotics resistance was assessed by five questions as shown in Figure 2. It was seen that 157 (13.9\%) participants had not followed the duration of treatment as given in their doctor's prescription, however, only 49 (4.4\%) changed their antibiotic dose without doctor consultation. There were 467 (41.3\%) participants who used leftover antibiotics from their previous prescription. It was alarming that there were 700 (61.8\%) participants who suggested it to their doctors to prescribe them antibiotics and 378 (33.4\%) participants who had purchased antibiotics without any prescription in the last one year (Figure 2). 


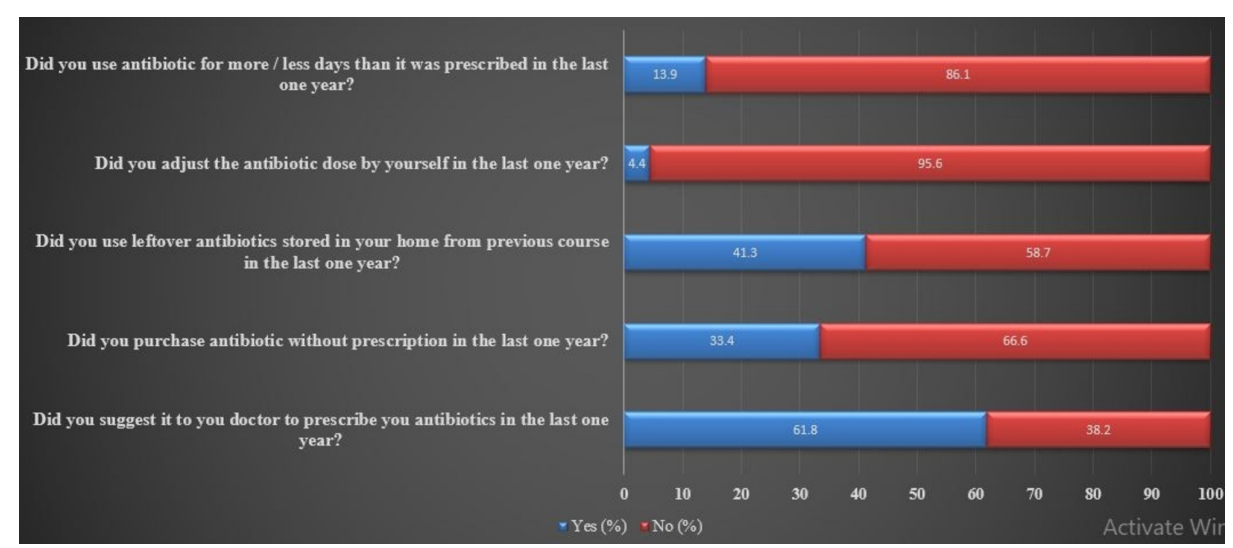

FIGURE 2: Assessment of attitude about antibiotic resistance (\%).

\section{Discussion}

Irresponsible and inappropriate prescriptions of antibiotics are among the major reasons contributing to the rising antimicrobial resistance. Almost one-third of the participants in this study took antibiotics without prescription. A study published in 2016 stated that over the counter sales of antibiotics is one of the major reasons for higher prevalence of resistance in the developing countries [11]. Inappropriate antimicrobial use by patients even with true bacterial infections can lead to failure of treatment and can mask various clinical symptoms associated with the disease [12]. Incorrectly managed patients - either who received antibiotics in absence of bacterial infection or who received incorrect drug or who received treatment for sub-optimal duration - essentially took antibiotics without any benefit and efficacy. Non-prescription antimicrobial use has been linked with severe adverse events including death [13, 14]. In this study, $41 \%$ of the participants used left over antibiotics from their own or someone else's previous antibiotic course. This practice of using left over antibiotics from previous antibiotic course may lead to increased use of antibiotics for short duration especially for viral infections, which may lead to antibiotic resistance [15]. There were $19 \%$ participants who believed that antibiotics can be taken in viral infections. A study published in 2017 stated that $18.3 \%$ of office-based visits for viral diseases resulted in antibiotic prescriptions [16].

The public health sector in Pakistan has recognized antibiotic resistance as its major health concern. In 2017, National Antimicrobial Resistance Action Plan was created for Pakistan. Its major strategic priority is "Development and implementation of a national awareness raising and behavioral change strategy on antimicrobial resistance [17]." This study serves as a supporter to this national action plan and highlights the key lacking in awareness and behaviors.

The urgent need for implementing antibiotic stewardship programs in Pakistan has been highlighted previously [18]. However, no aggressive measures have been taken yet. The attitude of the general population towards utilization of antibiotics is not very promising and needs immediate correction. Specialists of public health and infectious diseases in Pakistan have to join hands in initiating awareness programs and campaigns to educate the general masses regarding the preciousness of antibiotics.

\section{Conclusions}

Pakistani individuals are not as knowledgeable about antibiotic resistance as severe the issue is in this region. Their attitude towards utilization of antibiotics is not very promising. The rapidly rising trend in antibiotic resistance is becoming a public health concern in Pakistan. It has become essential to initiate antibiotic stewardship programs and educate the masses regarding efficacious and safe use of antibiotics in this region.

\section{Additional Information \\ Disclosures}

Human subjects: Consent was obtained by all participants in this study. Advance Educational Institute and Research Center (AEIRC) issued approval MU/ECA/20/559. 6th December 2018, Sundus Fareed Approval for Ethical Clearance of Research Project entitled "Knowledge and Attitude of the General Pakistani Population Towards Antibiotic Resistance" Reference is made to the above heading. I am pleased to inform you that the chairman has on behalf of the AEIRC ethics committee members, approved ethical clearance of the above mentioned Research Project based on recommendation of the AEIRC ethics committee meeting held on 3rd December 2018. The favorable opinion is given for a period of 1 year from the date of this letter. The opinion may be reviewed for a further period on receipt of a fresh application. The validity of this ethical clearance is effective from 6th December 2018. Animal subjects: All authors have confirmed that this study did not 
involve animal subjects or tissue. Conflicts of interest: In compliance with the ICMJE uniform disclosure form, all authors declare the following: Payment/services info: All authors have declared that no financial support was received from any organization for the submitted work. Financial relationships: All authors have declared that they have no financial relationships at present or within the previous three years with any organizations that might have an interest in the submitted work. Other relationships: All authors have declared that there are no other relationships or activities that could appear to have influenced the submitted work.

\section{References}

1. Nathan C, Cars O: Antibiotic resistance-problems, progress, and prospects. N Engl J Med. 2014, 371:17611763. 10.1056/NEJMp1408040

2. Nathan C: Antibiotics at the crossroads. Nature. 2004, 431:899-902. 10.1038/431899a

3. Davies J, Davies D: Origins and evolution of antibiotic resistance. Microbiol Mol Biol Rev. 2010, 74:417-433. 10.1128/MMBR.00016-10

4. Read AF, Woods RJ: Antibiotic resistance management. Evol Med Public Health. 2014, 2014:147. 10.1093/emph/eou024

5. Lushniak BD: Antibiotic resistance: a public health crisis. Public Health Rep. 2014, 129:314-316. $10.1177 / 003335491412900402$

6. The World Medicines Situation 2011. (2011). Accessed: February 11, 2019: https://www.who.int/medicines/areas/policy/world_medicines_situation/WMS_ch6_wPricing_v6.pdf.

7. Awad A, Eltayeb I, Matowe L, Thalib L: Self-medication with antibiotics and antimalarials in the community of Khartoum State, Sudan. J Pharm Pharm Sci. 2005, 8:326-331.

8. The global infectious disease threat and its implications for the United States . (2000). Accessed: February 11, 2019: https://www.dni.gov/files/documents/infectiousdiseases_2000.pdf.

9. Shahid A, Iftikhar F, Arshad MK, Javed Z, Sufyan M, Ghuman RS, Tarar Z: Knowledge and attitude of physicians about antimicrobial resistance and their prescribing practices in Services hospital, Lahore, Pakistan. J Pak Med Assoc. 2017, 67:968-972.

10. Limaye $\mathrm{D}$, Ziesenis $\mathrm{P}$, Limaye $\mathrm{V}$, et al.: Knowledge, attitude and practices of antibiotic usage among university students from Karachi, Pakistan. Int J Res Med Sci. 2019, 7:519-525. 10.18203/23206012.ijrms20185502

11. Bryce A, Hay AD, Lane IF, Thornton HV, Wootton M, Costelloe C: Global prevalence of antibiotic resistance in paediatric urinary tract infections caused by Escherichia coli and association with routine use of antibiotics in primary care: systematic review and meta-analysis. Bio Med J. 2016, 352:1939. 10.1136/bmj.i939

12. Liu YC, Huang WK, Huang TS, Kunin CM: Inappropriate use of antibiotics and the risk for delayed admission and masked diagnosis of infectious diseases: a lesson from Taiwan. Arch Intern Med. 2001, 161:2366-2370. 10.1001/archinte.161.19.2366

13. Feinfeld DA, Ansari N, Nuovo M, Hussain A, Mir R: Tubulointerstitial nephritis associated with minimal self reexposure to rifampin. Am J Kidney Dis. 1999, 33:e3. 10.1016/S0272-6386(99)70443-9

14. Ryrie DR, Fletcher J, Landman MJ, Daniels HE: Chloramphenicol over the counter. Lancet. 1973, 1:150.

15. Llewelyn MJ, Fitzpatrick JM, Darwin E, et al.: The antibiotic course has had its day . Bio Med J. 2017, 358:j3418. 10.1136/bmj.j3418

16. Imanpour S, Nwaiwu O, McMaughan DK, DeSalvo B, Bashir A: Factors associated with antibiotic prescriptions for the viral origin diseases in office-based practices, 2006-2012. JRSM Open. 2017, 8:1-8. $10.1177 / 2054270417717668$

17. Antimicrobial Resistance, National Action Plan, Pakistan. (2017). Accessed: February 19, 2019: https://www.nih.org.pk/wp-content/uploads/2018/08/AMR-National-Action-Plan-Pakistan.pdf.

18. Khan EA: An urgent need for National Action Plan for Infection Control and Antibiotic Stewardship in Pakistan. J Pak Med Assoc. 2016, 66:1201-1202. 